\title{
SUL-AMERICANOS NA GRANDE SÃO PAULO: Pesquisa-ação na Conferência Nacional de Migração e Refúgio e o diagnóstico dos imigrantes sobre a marginalização de direitos no Brasil // cynthia Soares
}

\section{Carneiro $^{1}$}

\section{Palavras-chave}

imigração / sul-americanos / mercosul / comigrar

HIIIIIIIIIIIIIIIIIIIIIIIIIIIIIIIII

\section{Sumário}

\section{Introdução}

2 A Conferência Nacional sobre Migração e Refúgio (Comigrar) e a opção pela pesquisa-ação

3 As razões que levaram à Comigrar e à consulta ao imigrante

4 Igualdade de direitos e marco legal: o princípio da não discriminação

5 Acesso ao direito de defesa, devido processo e execução da pena em condição de igualdade com brasileiros

6 Direito à participação política e ao voto

7 Acesso a cargos qualificados e carreira pública

8 Conclusão

9 Referências

\section{Resumo}

0 artigo relata resultado parcial de pesquisa que analisa a visão do imigrante sul-americano residente na Grande São Paulo acerca do sistema jurídico brasileiro relativo a recepção e permanência de estrangeiros no país e, uma vez estabelecidos no território brasileiro, os problemas relativos ao acesso a direitos fundamentais por parte dessa população específica. A pesquisa concentrou-se nos imigrantes sul-americanos em estado de vulnerabilidade para uma análise sobre a efetividade dos Acordos de Residência no Mercosul. Relata as dificuldades metodológicas acerca do estudo sobre migrações internacionais, principalmente quando considerada a população migrante em vulnerabilidade, e o processo de realização da Conferência Nacional sobre Migrações e Refúgio (Comigrar), evento que proporcionou a participação direta do imigrante no levantamento dos problemas legais relativos aos estrangeiros no Brasil.
1 Professora do curso de graduação e pós-graduação stricto senso da Faculdade de Direito de Ribeirão Preto-USP. Responsável pelas disciplinas Direito Internacional Privado, Direito da Integração Regional, Migrações Internacionais e Direito do Estrangeiro no Brasil e Arquitetura Internacional dos Direitos Humanos. Instituição financiadora: Fundação de Amparo à Pesquisa do Estado de São Paulo - FAPESP. 


\section{SOUTH AMERICANS IN THE GREATER SÃO PAULO: Participation in National Conference on migration and refuge and their diagnosis of the effectiveness of rights in Brazil // Cynthia Soares Carneiro}

\section{Keywords}

immigration / south americans / mercosur / comigrar

\begin{abstract}
This article reports partial results from a research that analyzes the perceptions about Brazilian legal system among a group of South Americans immigrants living in the Greater São Paulo area. More specifically, the research gather data on the perception of reception and stay of foreigners in the country and, once they are established in Brazil, the problems related to the access to fundamental rights. The research focused on vulnerable South American immigrants, in order to do an analysis of the effectiveness of Mercosur Residence Agreement. The article reports the methodological difficulties about the study of international migration, especially when considering the vulnerable migrants. Besides, the article discusses the organization of the National Conference on Migration and Refuge, a governmental event that provided an opportunity for immigrants to have a direct participation in debates about legal issues related to foreigners in Brazil.
\end{abstract}




\section{Introdução}

O artigo é o relato de pesquisa de natureza empírica qualitativa que coletou e analisou dados relativos ao trabalhador sul-americano no Brasil, especialmente no estado de São Paulo. A pesquisa de campo deu-se com o contato com grupos organizados de imigrantes e com responsáveis por associações civis de acolhida, para identificar percepções sobre questões jurídicas relativas à chegada e à permanência desses imigrantes no Brasil, bem como os entraves ao acesso a direitos fundamentais.

O público-alvo da pesquisa foram os imigrantes originários dos países signatários dos Acordos de Residência do Mercosul em situação de vulnerabilidade econômica, situação que favorece a exploração do trabalho, principalmente quando os imigrantes estão em situação irregular no território brasileiro.

No início da investigação, supunha-se que em face dos acordos bilaterais de regularização migratória firmados entre Brasil e Bolívia em 2005 e, posteriormente, com a vigência dos acordos de residência, em 2009, estaria assegurada a migração para o Brasil de pessoas originárias dos Estados signatários, e que esses imigrantes, portanto, estariam todos regulares. No entanto, com o desenvolvimento da pesquisa, essa hipótese não se verificou, pois grande parte desses imigrantes ainda permanece indocumentada.

Para levantar os dados que subsidiaram a pesquisa acompanhamos o trabalho da Missão Scalabriniana Nossa Senhora da Paz, que abriga o Centro de Estudos Migratórios, o Centro Pastoral dos Migrantes e a antiga Casa do Migrante, que atualmente encontra-se desativada e substituída pelo Centro de Referência e Acolhida para Migrantes (CRAI). Acompanhamos também o trabalho do Centro de Direitos Humanos e Cidadania do Imigrante (CDHIC) e do Centro de Apoio ao Migrante (CAMI), ambos sediados na cidade de São Paulo, além da Cáritas-SP, associação que cuida do acolhimento e atendimento aos solicitantes de refúgio, vinculada à Arquidiocese de São Paulo, bem como do Centro de Defesa de Direitos Humanos Padre João Bosco Burnier (CDDH-Pe. João Bosco), ligado à Mitra Diocesana, e situado na cidade de Guarulhos-SP.

Para a identificação da população imigrante e cole- ta de dados, tanto de natureza quantitativa quanto qualitativa, estabelecemos contato com instituições públicas na busca de estatísticas oficiais e no acompanhamento de elaboração e execução de políticas públicas voltadas ao trabalhador imigrante no Brasil.

Entre os órgãos públicos consultados, relacionamos a Secretaria Municipal de Direitos Humanos e Cidadania de São Paulo, especialmente a sua Coordenadoria de Políticas para Migrantes; visitamos delegacias especializadas em migração junto a postos da Polícia Federal, particularmente na cidade de Ribeirão Preto-SP; o Ministério do Trabalho e Emprego, especialmente através do seu Conselho Nacional de Migração (CNIG);o Ministério da Justiça, especialmente com a Secretaria Nacional de Justiça, o Departamento de Estrangeiros e o Conselho Nacional para o Refugiado (Conare).

Nesse aspecto, destacamos o trabalho que passou a ser desenvolvido, no curso desse processo de investigação, pelo Observatório das Migrações (OBMigra), grupo de pesquisa da UnB que atua em parceria com o Ministério do Trabalho. Este tipo de convênio contribui para desfazer as lacunas relativas aos dados quantitativos referentes às migrações sul-americanas para o Brasil na última década (2005-2015).

\section{A Conferência Nacional sobre Migração e Refúgio (Comigrar) e a opção pela pesquisa-ação}

Em razão dos percalços metodológicos que envolvem pesquisas com pessoas, ainda mais potencializados no caso da abordagem de estrangeiros, a análise sobre a imigração sul-americana e sua condição jurídica no Brasil somente fluiu de forma satisfatória quando se optou pela modalidade de pesquisa-ação, em razão do próprio formato conferido a Comigrar, que possibilitou a efetiva participação de integrantes do Grupo de Estudos Migratórios e do Trabalhador Imigrante no Brasil (GEMTI-FDRP).

Dessa forma, a condição de expectadores nas audiências públicas realizadas, a partir de 2012, por iniciativa do Ministério da Justiça, da Assembleia Legislativa do Estado de São Paulo e do governo municipal da cidade de São Paulo, com acompanhamento e assessoria da Organização Internacional para Migração 
(OIM), ocasiões em que eram elaborados os diários de campo, foram substituídas pela participação ativa dos pesquisadores acadêmicos no debate e na formulação de propostas durante as conferências parciais realizadas no âmbito da Comigrar.

No início da pesquisa, o trabalho de campo estava voltado à aplicação de questionários semiestruturados. No entanto, rapidamente foi possível perceberas dificuldades apresentadas ao levantamento do perfil do imigrante e de seus problemas e demandas jurídicas no Brasil. Foi possível notar, na abordagem de imigrantes em situação de vulnerabilidade jurídica ou econômica, sua desconfiança em relação aos entrevistadores, pois mais pareciam coagidos a aceitar a proposta da entrevista do que em cedê-las espontaneamente, evidenciando, assim, a dificuldade em se obter respostas fidedignas aos questionários. Este aspecto, entretanto, demonstra os efeitos sociais de uma legislação opressora, principalmente quando se trata de imigrantes indocumentados.

Essas percepções relatadas pela equipe de pesquisadores que foram a campo destacaram a imprescindibilidade de se trabalhar, principalmente, com o registro de notas tomadas nas reuniões com os imigrantes realizadas nas audiências públicas promovidas pelos órgãos mencionados. Nessas reuniões, foi possível registrar, de forma mais abrangente e realista, a percepção dos imigrantes sobre a burocracia migratória e as dificuldades de acesso a direitos constitucionais no Brasil.

Desde as primeiras reuniões preparatórias para a Comigrar, no primeiro semestre de 2013, a equipe de pesquisadores foi levada a uma mudança de postura: de meros observadores, que buscam não intervir ou, pelo menos, minimizar sua intervenção junto ao público estudado, passamos a atuar como coparticipantes do processo de identificação das demandas e, especialmente, na formulação de propostas de solução para os problemas apontados, fossem de caráter administrativo ou legal. Enfim, os pesquisadores estariam presentes, ao lado dos imigrantes e de suas associações de apoio, não apenas como observadores críticos, mas como atores do processo de consulta (PAULON, 2005). No entanto, os acadêmicos partiam do pressuposto de que os imigrantes são, de fato, os detentores do saber sobre as questões pro- postas pela Comigrar, embora estivéssemos melhor instrumentalizados para o esclarecimento das questões jurídicas colocadas por eles.

Portanto, em razão do caráter conferido ao evento por seus organizadores, a pesquisa desenvolveu-se por meio de uma relação proativa e recíproca entre o pesquisador e o objeto de seu estudo, confundindo os polos de uma investigação acadêmica clássica. Assim, além de identificar a dimensão do problema analisado, determinar suas causas e efeitos e apresentar algumas soluções possíveis, os pesquisadores propuseram-se, igualmente, a interferir no processo de consulta aos imigrantes, de forma a contribuir para a mudança da situação detectada e não desejada. Esse método foi desenvolvido por Michel Thiollent e denominado pesquisa-ação (THIOLLENT, 2002). Uma investigação que assuma este caráter está, necessariamente, imbricada com a extensão universitária, pois exige um contato permanente e direto com a população imigrante, o que inclui a atuação no sentido de atender as necessidades expostas e que estão ao alcance das habilidades acadêmicas (THIOLLENT, 2002).

Para essas consultas públicas foram, inicialmente, convidados órgãos oficiais, como o Ministério do Trabalho e Emprego, o Departamento da Polícia Federal e a Defensoria Pública, vinculada à Advocacia Geral da União, os grupos de pesquisa cadastrados junto à OIM, mas, principalmente, as associações civis de acolhida a imigrantes e de defesa de direitos humanos associados às questões migratórias, como o Instituto de Migrações e Direitos Humanos (IMDH), sediado em Brasília, que compareceram em todas as ocasiões representadas por pessoas migrantes.

As audiências públicas preparatórias culminaram com a realização da I Conferência Nacional sobre Migrações e Refúgio (Comigrar), promovida pela Secretaria Nacional de Justiça, órgão do Ministério da Justiça, e realizada entre novembro de 2013 e maio de 2014 sob a forma de múltiplas conferências parciais, na modalidade de conferências municipais, quando organizadas por órgãos públicos; conferências livres, promovidas por iniciativa de associações de imigrantes; e conferências virtuais, meio utilizado por brasileiros residentes fora do Brasil e por órgãos de dimensão nacional, como a Defensoria Pública da 
União, o que permitiu cobrir diversos municípios com presença significativa de imigrantes, distribuídos em vários estados brasileiros.

A equipe acompanhou e participou da Comigrar desde seus simpósios preparatórios, da realização da Conferência Municipal de São Paulo e das Conferências Livres promovidas por comunidades de imigrantes sul-americanos e associações de acolhida sediadas no município de São Paulo e cidades do seu entorno, especialmente, na cidade de Guarulhos, importante centro de residência para pessoas provenientes da Bolívia, Peru e Paraguai, e, finalmente, da conferência final, que congregou, na etapa nacional, delegados eleitos em cada uma das conferências parciais, em quaisquer de suas modalidades, que se realizou entre os dias 30 de maio e $1^{\circ}$ de junho de 2014, na cidade de São Paulo, capital do estado de São Paulo, maior centro brasileiro de atração de migrantes internacionais.

Com a realização da Comigrar, foi possível identificarmos outras associações de imigrantes (Instituto Terra, Pátria Inca, Migrantes Bolivianos no Brasil) e de apoio a imigrantes, além daquelas inicialmente cadastradas junto à OIM e órgãos oficiais. Essas associações mobilizaram-se para a realização das chamadas conferências livres, o que também estimulou a organização de outros grupos de imigrantes, originando, ao menos naquele contexto, novas associações, que permaneceriam na invisibilidade se não fosse a iniciativa governamental de promover a participação ampla e direta dessas entidades, que resultou em um foro de debates sobre política migratória e de denúncia de violação de direitos composto quase que exclusivamente por estrangeiros, se não fosse a presença e a participação de acadêmicos e pesquisadores brasileiros.

No curso dos eventos de consulta, algumas medidas administrativas de importância significativa, levantadas desde as primeiras audiências públicas, em 2012, foram regulamentadas por resoluções normativas do Ministério da Justiça ou objeto de políticas municipais. São exemplos de medidas tomadas pelo governo federal, a retirada da identificação do status de refugiado no Registro Nacional de Estrangeiros (RNE), que ensejava a discriminação do portador, e o convênio com a DPU, que atualmente acompanha os procedimentos de ingresso e saída compulsória do imigrante e as solicitações de refúgio, além de acompanhar procedimentos judiciais e administrativos em defesa do imigrante. Sobre as medidas na esfera municipal, na cidade de São Paulo, houve a criação da Coordenação de Políticas para Migrantes, órgão vinculado à Secretaria Municipal de Direitos Humanos e Cidadania, e a criação do Centro de Referência e Atendimento ao Imigrante (CRAI), complementando um atendimento que era realizado exclusivamente pelas associações civis de apoio.

No estreitamento do contato com organizações de migrantes em São Paulo e Guarulhos, viabilizados pelos eventos promovidos tanto pela Secretaria Nacional de Justiça como pela Coordenação de Políticas para Migrantes, da cidade de São Paulo, foi possível aferir o grau de efetividade das normativas mercossulinas, ou seja, dos acordos de residência e livre-circulação ratificados pelos Estados-Membros e Associados do Mercosul.

Apesar de o direito de integração regional ter sido formalmente internalizado e implementado pelo Estado brasileiro, ainda persiste um grande número de imigrantes sul-americanos irregulares no país, e a pesquisa apontou como causa a burocracia administrativa de ambos os Estados envolvidos no processo migratório, o que cria obstáculos ao acesso, inclusive, a direitos constitucionalmente estabelecidos. 0 que é concedido pelo tratado regional, a norma procedimental interna denega. Esse fator é a origem das demais restrições legais a que estão submetidos os trabalhadores estrangeiros, dentre as quais a mais significativa é a de impedir a regularização de sua permanência e, em consequência, do contrato de trabalho, fator que leva à subcontratação e precarização de direitos, um fenômeno que, nos tempos atuais, é internacional, não apenas brasileiro, como demonstram os estudos sobre o tema (HIRATA, 2006; CALAVITA, 2010; BSR, 2008).

Com a publicação dos Cadernos da Comigrar (BRASIL, MJ; 2014) foram analisadas as demandas apresentadas e/ou emendadas pelos imigrantes sul-americanos residentes na região da Grande São Paulo, cotejando-as com normas de Direito Internacional, especialmente as convenções multilaterais e acordos 
bilaterais entre Estados da América do Sul, as normativas de direito de integração regional provenientes do Mercosul relativas à livre circulação de trabalhadores, para abordar, finalmente, o direito nacional relativo aos estrangeiros: essencialmente a Lei 6.815/80 e as resoluções normativas do CNIg, além do Projeto de Lei 5.655/2009, em trâmite no Congresso Nacional durante a realização da Comigrar, e o Anteprojeto de Lei de Migrações, elaborado por especialistas nomeados pelo Ministério da Justiça ${ }^{2}$ e apresentado, em duas audiências públicas, antes da etapa nacional da Comigrar. ${ }^{3}$

O fato é que, com a realização da Comigrar, foi possível o levantamento de um grande volume de dados que seria absolutamente inviável de serem obtidos por outra forma. Após o término da etapa nacional foram sistematizadas mais de 2.500 propostas, que recomendam desde reformas constitucionais, como a sugestão de alterar competências atribuídas à Polícia Federal e a de atribuir direitos políticos aos estrangeiros, até atos administrativos de rito simplificado, como são as resoluções normativas ou portarias ministeriais.

Ao mesmo tempo, já estava em trâmite no Congresso Nacional o projeto de lei sobre o direito do estrangeiro no Brasil: o PL 5655/20094, de iniciativa do Poder Executivo, identificado como novo Estatuto do Estrangeiro. Enquanto ocorriam os debates públicos foi apresentado pelo senador Aloysio Nunes o antigo PLS $228 / 13^{5}$, atualmente identificado por PL

\footnotetext{
2 Portaria $n^{\circ} 2.162 / 2013$.

3 Realizadas nos dias 23 de agosto de 2013, na sede da Procuradoria Regional da República $3^{a}$ Região, na cidade de São Paulo, e no dia 6 de maio de 2014 no campus da USP, também em São Paulo. 4 Disponível em: <http://www.camara.gov.br/proposicoesWeb/fic hadetramitacao?idProposicao=443102>. Acesso em: 19 mar. 2015. 5 Disponível em: <http://www.senado.gov.br/atividade/materia/ detalhes.asp?p_cod_mate=113700>. Acesso em: 19 mar. 2015 “Dispõe sobre os direitos e deveres do migrante e regula a entrada e estada de estrangeiros no Brasil, revogando, em parte, o Estatuto do Estrangeiro (Lei n 6.815/80). Regula os tipos de visto necessários para ingresso de estrangeiros no país. Estabelece os casos e os procedimentos de repatriação, deportação e expulsão. Dispõe sobre a naturalização, suas condições e espécies e os casos de perda de nacionalidade. Trata da situação do emigrante brasileiro no exterior. Tipifica o crime de tráfico internacional de pessoas para fins de migração e infrações administrativas relativas a entrada irregular no país. Altera a Lei n 8.213/91 (Previdência Social), para facilitar a contribuição à Previdência do trabalhador brasileiro referente ao período em que tenha trabalhado em país estrangeiro".
}

2516/2015, intitulado Lei de Migrações. Anteriormente, o mesmo senador já havia apresentado o Projeto de Emenda Constitucional 25/2012 ${ }^{6}$, no sentido de permitir,em eleições municipais, capacidade eleitoral ativa e passiva ao imigrante com residência permanente no Brasil.

Em resposta às críticas levantadas por pesquisadores acadêmicos, representantes de associações de acolhida e pelos próprios imigrantes aos projetos apresentados, o Ministério da Justiça providenciou a elaboração de um novo anteprojeto de Lei de Migrações e deu início ao processo de rediscussão dos projetos propostos. Foi nessas instâncias que levantamos todos os dados analisados na pesquisa, pois nesses encontros os coletivos de imigrantes expuseram suas queixas e suas demandas relativas às violações a direitos fundamentais a que são, frequentemente, submetidos.

A avaliação do papel desempenhado pela Polícia Federal e da forma como se dá a prestação do serviço mostrou-se relevante em razão das demandas suscitadas pelo próprio movimento de defesa dos direitos migratórios, que criticam o fato de o controle ser feito pela Polícia Federal, o que conduz, inexoravelmente, à criminalização do imigrante irregular.

O fato de a Lei 6.815/80 tratar da questão migratória segundo o paradigma da segurança nacional e proteção do trabalhador brasileiro explica, inclusive, a grande dificuldade encontrada pelos estrangeiros na obtenção dos registros oficiais, justamente em face da larga discricionariedade do Estado em relação às questões migratórias e da burocracia imposta pelo serviço de atendimento ao imigrante. O princípio da segurança nacional, insculpido na Lei de Estrangeiros, dificulta até mesmo para advogados obterem acesso a informações relativas a processos administrativos de interesse do imigrante, mesmo quando atuam nos autos.

\section{As razões que levaram à Comigrar e à consulta ao imigrante}

A realização da Comigrar deu-se em razão de uma demanda governamental por uma ampla discus-

6 Disponível em: <http://www.senado.gov.br/atividade/materia/ detalhes.asp?p_cod_mate=105568>. Acesso em: 19 mar. 2015. 
são sobre a situação dos imigrantes no Brasil diante das críticas acadêmicas e das associações de acolhida à legislação restritiva vigente e também ao PL 5655/2009, enviado pelo Ministério da Justiça ao Congresso Nacional. Além disso, havia a necessidade de se buscar dados confiáveis acerca dos estrangeiros em situação de irregularidade administrativa e em estado de vulnerabilidade no Brasil, além de estabelecer um diagnóstico atual e mais preciso acerca das novas imigrações pelo levantamento de dados relativos ao perfil desse novo imigrante, das atividades desempenhadas no Brasil, de sua constituição familiar, sobre a manutenção de relações com o país de origem, para a remessa de divisas, por exemplo, e determinar sua concentração geográfica, posto que a Conferência deu-se em todo território nacional. Esse conhecimento é essencial para a elaboração de políticas públicas nacionais e locais, posto que o município é o espaço em que se evidenciam as necessidades dos imigrantes e suas famílias e o lugar onde se configuram as restrições a direitos.

Até 2014, os dados relativos ao número de indocumentados foram levantados, principalmente, junto a associações de atendimento, e, até então, eram praticamente os únicos disponíveis. Sua imprecisão, entretando, exigia que fossem analisados com restrições, pois deveria ser considerada a possível pluralidade de registros, em razão da peregrinação do imigrante vulnerável por todas as associações de acolhimento e apoio disponíveis. Em razão do aumento migratório dos últimos anos, a necessidade de se conhecer essa realidade foi igualmente percebida por órgãos públicos estaduais e municipais, como são exemplos as iniciativas tomadas pelo Estado do Paraná e pelo Município de São Paulo, nesse sentido.

No âmbito federal, a solução encontrada foi a realização de uma ampla conferência capaz de promover a participação de associações civis e religiosas de apoio ao imigrante, de pesquisadores acadêmicos, de representantes de órgãos da advocacia pública e dos agentes federais com competência para políticas migratórias, mas também, que fosse capaz de estimular a mobilização dos próprios imigrantes, de todas as origens, no processo de consulta promovido pelo Ministério da Justiça com apoio da Organização Internacional para Migrações (OIM).
Como resultado, a Comigrar, de fato, conferiu visibilidade a todo o espectro de imigrantes que se encontram, atualmente, no Brasil, que, até então, permaneciam acobertados pelo manto da burocracia restritiva e da exploração do trabalho.

Os diversos coletivos de imigrantes que participaram da Comigrar levantaram os problemas recorrentes enfrentados no Brasil, e foi possível identificar os obstáculos legais à aferição de direitos, mesmo daqueles sobre os quais não recaem as restrições constitucionais aos estrangeiros, como o direito a saúde e educação públicas. Foi igualmente destacada a dificuldade de acesso a serviços públicos e programas oficiais de assistência social disponíveis aos brasileiros.

Propostas e sugestões para solução dos problemas identificados foram apresentadas pelos coletivos de imigrantes e demais participantes, foram, em segui$\mathrm{da}$, referendadas e emendadas pelos delegados nacionais, e, finalmente, sistematizadas no Caderno de Propostas da I Conferência Nacional sobre Migrações e Refúgio (COMIGRAR, 2014).

A metodologia empregada foi desenvolvida nos primeiros colóquios de organização encaminhados pelo MJ/OIM, nos quais a identificação dos problemas a serem tratados e o levantamento de propostas deram-se em grupos de trabalhos heterogêneos, dos quais participavam imigrantes, associações civis, representantes do poder público e pesquisadores, alternados por grupos compostos exclusivamente por representantes de cada um desses setores. Em São Paulo, o primeiro desses colóquios ocorreu nos dias 20 e 21 de maio de 2013.

Definidos os temas centrais, as conferências realizadas no âmbito da Comigrar dividiram os participantes, conforme o interesse de cada um, em grupos de trabalho definidos por nuvens temáticas. Nessas ocasiões, as nuvens temáticas puderam ser mais bem definidas e desmembradas em outros subtemas submetidos a ajuste e complementação na etapa final da Comigrar, que se deu de 30 de maio a $1^{\circ}$ de junho de 2014, na cidade de São Paulo.

O primeiro grande tema, ou nuvem temática, é igualdade de direitos; o segundo, serviços locais; o terceiro, pro- 
cedimentos operacionais em programas e serviços públicos; o quarto tema, inclusão produtiva; o quinto, violação de direitos; e, finalmente, a sexta nuvem temática trata dos brasileiros no exterior e migrantes retornados.

Justamente porque identificados a partir da interlocução direta com os imigrantes, sujeitos que vivenciam uma condição de exclusão em face de um sistema jurídico discriminatório, os temas determinados refletem os problemas concretamente vivenciados por essa população. O eixo sobre igualdade de direitos espelha, cruamente, a discriminação e exclusão jurídica materialmente experimentada, apesar do princípio da não-discriminação por critério de nacionalidade ou de status jurídico no território do Estado já estar expresso em convenções internacionais, em declarações solenes de organismos internacionais e em acordos regionais, como são os acordos de residência mercossulinos, todos ratificados pelo Brasil e vigentes desde 2009.

As conferências livres realizadas em São Paulo possibilitaram a participação de um amplo espectro dos diversos povos que têm escolhido o Brasil como país de destino, principalmente na última década. Estiveram presentes grupos de haitianos, diversos povos africanos, representantes palestinos e de países árabes, e originários de países europeus, especialmente espanhóis e italianos. No entanto, o objeto da presente pesquisa restringiu-se ao imigrante proveniente de Estados sul-americanos, pessoas majoritariamente beneficiadas pelos tratados de livre circulação firmados no âmbito do Mercosul e Estados associados. Por isso, os aspectos abordados trataram, exclusivamente, das questões enfrentadas pelos imigrantes sul-americanos, e, como pode ser observado, são problemas inarredavelmente relacionados ao seu perfil socioeconômico.

Destacaremos, a seguir, algumas das principais demandas apontadas pela Conferência Municipal de São Paulo e pelas conferências livres realizadas na cidade pelas associações e coletivos, que, algumas vezes, chegaram a realizar mais de uma conferência livre, de forma a garantir a participação do maior número de pessoas possível. Todos os pontos abordados aqui foram originados ou receberam a adesão das associações que desenvolvem suas atividades no estado de São Paulo, atendendo imigrantes em estado de necessidades urgentes e de vulnerabilidade.
Necessário apontar que a participação majoritária foi de imigrantes da capital e cidades da Grande São Paulo. As propostas que não tiveram adesão dos grupos paulistas não foram relatadas neste trabalho.

\section{Igualdade de direitos e marco legal: 0 princípio da não discriminação}

A situação excepcional a que estão submetidos os estrangeiros no Brasil, por força de uma lei restritiva, é evidenciada logo na primeira proposta formulada na Comigrar. A proposta tem o caráter de reivindicação e de denúncia contra uma situação instaurada de marginalidade jurídica. Na proposta também vêm destacadas as formas de discriminação a que estão sujeitos os imigrantes no Brasil, uma discriminação institucional e social. Portanto, reivindica-se que, por instrumentos legais eficazes, possa ser garantida a efetividade do princípio da não discriminação, que surge entre os primeiros aspectos destacados pelos participantes, conferindo-lhe caráter de urgência e prioridade.

A não discriminação, princípio que aparece timidamente nos instrumentos internacionais do pós-guerra, de início assegurava apenas o tratamento igualitário entre nacionais e estrangeiros, proibindo, portanto, a discriminação pelo critério da nacionalidade. Entretanto, os tratados de então não deixaram de reconhecer e assegurar ao Estado o poder soberano de estabelecer medidas restritivas contra o estrangeiro indocumentado em seu território. Ocorre que o novo contexto internacional, com fluxos contínuos de migrantes econômicos que vão em busca de sobrevivência, trabalho e desenvolvimento para si próprios e suas famílias, não se ajusta mais às medidas restritivas de segurança que levam à presunção, oficial e social, de que o indocumentado possa ser um potencial criminoso ou, considerando justamente a conjuntura contemporânea, um terrorista internacional.

Instrumentos jurídicos posteriores, em especial no Mercosul, como suas declarações solenes, resoluções e acordos de residência, reconheceram a amplitude do espectro de ações que caracterizam a discriminação e os obstáculos impostos aos imigrantes para acessarem os meios para aferição de desmandos sofridos e a garantia de seus direitos. A importância dessas normativas mercossulinas é o reconhecimen- 
to jurídico de que a situação de irregularidade é a principal condição para que se desencadeie uma sucessão de violações a direitos fundamentais, inerentes à dignidade humana.

Os participantes da Comigrar identificaram e relacionaram formas de discriminação na proposta final submetida à avaliação e complementação dos delegados nacionais. Eles apontaram a necessidade de reforma legislativa para a efetivação de direitos constitucionalmente consagrados, embora ainda ineficazes para a população migrante. A primeira proposta apresentada traz, justamente, a seguinte recomendação ${ }^{7}$ :

Assegurar, através de aparatos legais, o pleno acesso aos direitos, liberdades e garantias fundamentais, individuais e coletivos, ao acesso à justiça e ao tratamento igualitário e não discriminatório entre brasileiros e estrangeiros, independentemente da sua origem, nacionalidade, condição socioeconômica, formação profissional ou status migratório, reconhecendo diversidades étnicas e culturais e de gênero, características específicas do fluxo migratório que originou o deslocamento, bem como elaborar parâmetros norteadores para o efetivo acesso a todos os serviços públicos, bem como assegurar o atendimento equânime, reduzir burocracias e eliminar barreiras de acesso aos processos de regularização migratória, emissão de documentos, a programas, serviços e benefícios sociais do governo. (Grifos nossos.)

Durante todo o processo de identificação dos problemas enfrentados pelos imigrantes sul-americanos no Brasil, a questão mais significativa, apontada como impeditiva ao acesso a direitos, foi a cobrança de taxas públicas para qualquer requerimento ou provimento de órgãos oficiais, medidas que inviabilizam que pessoas em situação de vulnerabilidade possam se estabelecer de forma regular e atender os critérios impostos pela burocracia do Estado, objeto de recomendações de reformas nos procedimentos administrativos. Na complementação dessa proposta, na

7 Proposta 1.1 do Caderno de Propostas. Formulada e/ou votada na Conferência Livre (CL) ArsEspLitz. SP. 27.03.2014; CL Caritas. SP. 27.03.2014; CL CDDHPe.João-SP 31.03.2014; CL IMASP. 22.03.2014; CL Missão Paz, 14.03.2015; CL Ref. Migrantes Bolivianos no Brasil, 19.03.2014; CL UniSantos, 19.03.2014. etapa final da Comigrar, mais uma vez foi destacada a necessidade de eliminação de taxas como forma de viabilizar, até mesmo, a emissão do documento de identidade do estrangeiro. Nesse aspecto, os imigrantes também relatam a demora injustificável na emissão - e se queixam dela de forma reiterada pela Polícia Federal, ou seja, pelo Ministério da Justiça, do Registro Nacional de Estrangeiro (RNE), o que impede que até mesmo as pessoas que têm todas as condições para uma estadia regular permaneçam em uma semirregularidade ou em um limbo jurídico por portar apenas um protocolo do requerimento de documentação feito no órgão competente.

Em relação à atuação da Polícia Federal, os delegados nacionais, em complementação a essas propostas, recomendaram para seus agentes cursos de formação e orientação sobre direitos humanos e a condição migrante, alegando que a situação especial vivida por essas pessoas é desconhecida pelos policiais federais, o que os leva a atuar de forma discriminatória, expondo o imigrante ao agravamento de sua situação, já precária, e submetendo-o a constrangimentos que poderiam ser evitados se houvesse entendimento mais adequado dos agentes públicos e policiais.

Ainda mais difícil de obtenção, em razão do alto custo das traduções oficiais, é o reconhecimento de títulos e diplomas, fator que também contribui para a precarização do trabalho até mesmo dos imigrantes que possuem qualificação maior em relação ao ofício que se veem na contingência de exercerem no Brasil.

Outra forma de discriminação apontada é a recorrente utilização da palavra estrangeiro, que os imigrantes recomendam ser trocada por "não brasileiro" ou migrante, pelo fato de que a própria palavra carrega, objetivamente, um caráter discriminatório. ${ }^{8}$ Assim, em razão da necessidade de recontextualizar a legislação brasileira e os procedimentos e práticas dos órgãos públicos, os delegados recomendaram a atualização dos conceitos legais relativos aos estrangeiros e refugiados, como mais uma forma de evitar discriminações e garantir o amplo acesso a direitos e serviços públicos no Brasil. Esse aspecto foi contem-

$8 \mathrm{~A}$ origem etimológica da palavra estrangeiro vem do latim, de extraneus, ou aquele que é estranho, de fora, não familiar. 
plado no anteprojeto de lei elaborado pelo grupo de especialistas, que destacaremos adiante.

A discriminação em razão da idade é outro problema que vulnerabiliza ainda mais imigrantes em situações já precárias, atingindo tanto jovens quanto idosos. Em relação aos jovens, a idade impossibilita ou dificulta a emissão de documentos e, portanto, restringe, na origem, qualquer possibilidade de aferição de direitos a crianças e adolescentes migrantes que se deslocam desacompanhados dos pais ou se encontram, no Brasil, na companhia de apenas um deles. Interessante notar que os participantes destacaram, nesse aspecto, outro princípio jurídico recepcionado por instrumentos convencionais e legais brasileiros que não tem sido aplicado aos imigrantes: o de meIhor tratamento a criança e adolescentes, em razão de sua condição objetiva de vulnerabilidade. Como indicativo, foi definido pelos delegados nacionais que "sempre que houver conflito na legislação sobre a proteção aos direitos das crianças e adolescentes, que esta prevaleça” (COMIGRAR, 2014). Situação análoga prejudica o idoso, para o qual se inviabiliza qualquer suporte previdenciário.

Também foi reportada a discriminação de gênero e orientação sexual, e relatado que um número significativo de imigrantes sofre problemas psicológicos provocados pela situação de instabilidade, fator ao qual devem ser somadas as diversas situações de abuso e discriminação a que estão submetidos, inclusive a falta de reconhecimento jurídico como sujeitos de direitos em condição de igualdade com brasileiros, o que os coloca em uma situação de inferioridade e precariedade (HONNETH, 2011).

Nota-se que muitas das medidas pleiteadas demandam ações urgentes de adequações de práticas e condutas administrativas com a finalidade de garantir direitos constitucionais a todos que vivem e trabalham no território nacional. A expedição de documento de identificação, a regularização de sua situação trabalhista, previdenciária e tributária no país não é de interesse apenas do imigrante, mas do próprio Estado, que deve adaptar-se para responder de forma adequada às demandas impostas por uma ordem internacional diferente daquela que vigorava em meados no século XX.

\section{Acesso ao direito de defesa, devido processo e execução da pena em condição de igualdade com brasileiros}

A primeira proposta formulada nas conferências preparatórias da Comigrar destaca a necessidade de assegurar aos imigrantes o pleno acesso a direitos em condição de igualdade com os nacionais, de resto, conforme determinação constitucional e convencional. Em relação ao acesso a direitos, foi destacada a categoria especial do acesso à Justiça, ao devido processo legal e a direitos de presas e presos imigrantes que cumprem pena em penitenciárias no Brasil.

Nos termos da Lei 6.815/80, o imigrante condenado no Brasil por crimes de razoável potencial ofensivo estará passível de expulsão, antes ou depois do cumprimento da pena, de acordo com a conveniência nacional. Assim, na legislação brasileira existem duas espécies de prisão: a que corresponde à execução da pena e a prisão administrativa, esta para garantia da expulsão. Não é raro que o imigrante fique detido após o cumprimento total da pena até que seja possível sua retirada do território brasileiro, prolongando sua reclusão de forma indevida, em flagrante violação ao direito do preso, o que lhe confere um tratamento diferente em relação ao condenado brasileiro por delito idêntico.

Outro fator identificado desde os colóquios iniciais, que contaram com a participação ativa de membros da Polícia Federal e da Defensoria Pública da União, além de membros do Ministério da Justiça, foi o regime diferenciado de progressão da pena para o condenado imigrante. Como a condição de condenado por crime praticado no Brasil cassa o seu título de ingresso, quando este existir, e como também impede a sua regularização no país, a partir da condenação e do pedido de expulsão, o estrangeiro egresso da prisão não possui qualquer documento de identificação no Brasil, além de ter o seu passaporte retido pela Polícia Federal. Como consequência, o beneficiário da progressão de regime seria mais um indocumentado sobre o qual o Estado não tem efetivo controle, o que justifica, nos termos da legislação vigente e de decisões judiciais em habeas corpus impetrados contra a reclusão ilegal, o cumprimento de toda a pena em regime fechado, independentemente do que é assegurado pelas leis penais e de execução penal no Brasil aos brasileiros em situação idêntica. 
Como esse obstáculo é real e depende não apenas da edição de alterações legislativas que contemplem especificamente a condição do preso estrangeiro, mas também da boa receptividade de juízes brasileiros que irão conhecer e decidir sobre o pedido, uma alternativa apresentada a esse problema foi a proposta de realização de acordos bilaterais entre Estados para garantir a possibilidade do cumprimento da pena no país de origem e/ou de nacionalidade do imigrante, quando assim for conveniente e requerido pelo próprio condenado.

Diante da denúncia dessa situação pelos membros da DPU, antes mesmo de encerrado o processo de consulta da Comigrar, o Ministério da Justiça editou, sobre a questão, a Resolução Normativa n 110, de 10 de abril de $2014^{9}$, que autoriza a concessão da permanência em caráter provisório, a título especial, para o imigrante que cumpra as condições legais estabelecidas para a progressão do regime de cumprimento de pena, de forma a estabelecer igualdade de condições com brasileiros. No entanto, uma resolução administrativa, justamente por estar suscetível a comandos normativos hierarquicamente superiores, como o da lei, não tem a mesma garantia de direitos oferecida pela norma instituída por via legislativa, que demanda procedimento público e transparente para sua revogação.

Em relação à expulsão do imigrante condenado por crime no Brasil, os participantes da Comigrar destacaram também o princípio da reunião do grupo familiar como argumento jurídico para evitar a saída compulsória do estrangeiro com família no Brasil.

Nesse aspecto, a Lei 6.815/80 prevê, como exceção à expulsão, a existência de casamento ou união estável no Brasil há mais de cinco anos ou a existência de filho brasileiro, exigindo ainda que acriança esteja sob guarda e dependência do seu genitor condenado, situação praticamente impossível de ser mantida em se tratando de um preso. Apesar das decisões reiteradas do Superior Tribunal de Justiça (STJ) e do

\footnotetext{
9 Disponível em <http://portal.mte.gov.br/data/files/8A7C816A4 54D74C10145992F8E7D517E/RESOLUÇÃO\%20110\%20-\%202014. pdf>. Acesso em 21 mar. 2015.
}

Supremo Tribunal Federal (STF) ${ }^{10}$, com fundamento no Estatuto da Criança e do Adolescente, no sentido de ampliar as situações excepcionais a permitir a permanência do egresso da prisão no Brasil, independentemente da condição econômica do genitor egresso, os projetos de lei em trâmite no Congresso Nacional não consideraram o entendimento já firmado de que a criança e o adolescente tem o direito a permanecer em contato com o pai e a mãe para sua segurança afetiva e psicológica, que vem plenamente ao encontro do princípio da reunião familiar expresso em convenções internacionais de direitos humanos.

Ante esses problemas, foram apresentadas pelos imigrantes propostas de alteração legislativa, de mudanças de práticas administrativas e desenvolvimento de políticas públicas voltadas à solução dos problemas decorrentes da situação de homens e muIheres migrantes que se encontram em penitenciárias do Brasil, de forma que possam receber tratamento equivalente ao de brasileiros presos. A proposta, que também cuida da não criminalização do imigrante irregular, foi redigida nos seguintes termos ${ }^{11}$ :

Realizar alterações legislativas com foco na isonomia processual e de direitos entre brasileiros e estrangeiros que cumprem pena no Brasil, bem como tratamento humanitário e digno, assegurando que a detenção não aconteça por motivo migratório e implementando medidas como garantia de comunicação com a família, oportunidade de trabalho e esporte dentro da prisão, curso de português, assistência jurídica pública e à defensoria pública, acesso ao setor jurídico do sistema penitenciário e à legislação penal, direitos e deveres internos à penitenciária em diversos idiomas e intérprete para solicitar esclarecimentos e receber informações processuais, julgamento dentro (do) prazo estipulado por lei, guarda de pertences, acesso a correspondências, objetos básicos de higiene, roupas adequadas à temperatura local, itens de limpeza, acesso à saúde, educação, livre manifes-

10 BRASIL. STF. RE 608898 RG / SP - SÃO PAULO. REPERCUSSÃO GERAL NO RECURSO EXTRAORDINÁRIO. Relator(a): min. MARCO AURÉLIO. Julgamento: 10/03/2011.

11 Proposta 1.2. Formulada e/ou votada pela CL Cáritas. SP. 20.03.2014; CL CDDHPeJoão, 31.03.2014; CL Inst.Terras.SP, 24 e 29.03.2014; CL DPU 31.03.2014. 
tação religiosa e trabalho remunerado e benefícios de regime semiaberto, liberdade condicional, progressão de pena, visita conjugal, permissão ao preso estrangeiro que tem residência fixa no Brasil responder o processo em liberdade, indulto para os enfermos com doenças irreversíveis e direito à permanência no Brasil após o nascimento do filho no país.

Durante o processo de consulta, e principalmente por ocasião da complementação final das propostas pelos delegados nacionais, evidenciou-se a preocupação das comunidades migrantes e, principalmente, das associações de assistência e apoio, que estão em contato permanente com a família do imigrante, de assegurar a reunião familiar, destacando a necessidade de se tornar explícita por norma a proteção da família migrante, a identificação da união estável com casamento, o reconhecimento de formas mais amplas de família do que aquela tradicionalmente concebida pela lei brasileira, de forma que seja também garantida a esses familiares a visita ao preso, a garantia do direito de permanência no Brasil também de filhos estrangeiros, independentemente de sua idade, garantindo-se, assim, a manutenção da convivência familiar.

Além da questão dos imigrantes, propriamente ditos, a preocupação com a expulsão do estrangeiro devido à prática de crimes é mais relevante quando se trata de um refugiado, que obteve essa condição no Brasil em razão de ter comprovado que está sujeito a sérias e urgentes ameaças a sua vida e integridade física no país de origem ou de procedência. Por isso o instituto do refúgio é caracterizado por impedir a devolução do refugiado ao território de onde precisou fugir. Portanto, o efeito da expulsão é vedado ao refugiado e isso precisa ser expressamente reconhecido por lei para que não dê margem a equívocos que possam importar em grave violação de direitos que foram expressamente recepcionados pelo Estado brasileiro. ${ }^{12}$

12 Lei 9474/97. Da expulsão Art. 36. Não será expulso do território nacional o refugiado que esteja regularmente registrado, salvo por motivos de segurança nacional ou de ordem pública. Art. 37. A expulsão de refugiado do território nacional não resultará em sua retirada para país onde sua vida, liberdade ou integridade física possam estar em risco, e apenas será efetivada quando da certeza de sua admissão em país onde não haja riscos de perseguição.
Outro problema identificado e relatado tratou das dificuldades especiais enfrentadas pela mulher presa. Entre elas, as mais comuns estão justamente relacionadas aos seus filhos que podem cair no abandono, especialmente quando não há no Brasil membros da família que possam se responsabilizar pelas crianças. Para esses casos se recomenda a alteração da legislação sobre execução de penas, criando a possibilidade de cumprimento da pena em prisão domiciliar quando a condenada tiver filhos pequenos sob sua responsabilidade.

A educação do preso durante o cumprimento da pena também teve destaque nos debates sobre a matéria. Como o aspecto linguístico é reconhecido como fator limitante dos direitos do preso a um devido processo legal, posto que, muitas vezes, o imigrante não pode compreender com precisão o idioma no qual é desenvolvido o processo, os imigrantes e suas associações de apoio apontam a necessidade de cursos de português na prisão para condenados estrangeiros, bem como curso de outros idiomas para agentes penitenciários incumbidos de atender presos estrangeiros.

Em relação à condição do condenado no Brasil e de seus direitos relacionados à educação, aqui o portador de diploma universitário possui situação mais benéfica que os demais presos comuns, o que poderia auferir benefícios ao imigrante titulado no cumprimento de sua pena. Essa situação reitera a necessidade de mudanças nas regras para o reconhecimento ou validação de cursos e títulos regularmente obtidos no exterior, aspecto que foi levantado pelos participantes da Comigrar em grupos de trabalho distintos de forma recorrente. A demanda dos imigrantes é tanto pelo reconhecimento da equivalência dos estudos realizados no país de origem ou de procedência, aos critérios estabelecidos pelo sistema educacional brasileiro, quanto pela possibilidade de continuar seus estudos enquanto estiver preso. Em relação ao reconhecimento do diploma universitário a demanda é, igualmente, pela desburocratização do procedimento de forma a garantir o exercício do direito profissional no Brasil e os seus efeitos no sistema de execução de pena. Nesse aspecto, como o processo de validação e legalização de títulos é lento e oneroso, pleiteia-se o reconhecimento do título obtido no exterior nos termos em que lhe foi conferida a validade pela legislação estrangeira. 
Os participantes indicaram ainda a necessidade da promoção integral da saúde dos imigrantes presos, tanto com programas de promoção de tratamento médico quanto de prática de esportes na prisão, de prevenção de doenças e reabilitação. Requerem que haja destaque especial para a condição do preso com doenças terminais.

\section{Direito à participação política e ao voto}

$\mathrm{O}$ acesso a direitos fundamentais e a igualdade real com os brasileiros implica conceder ao imigrante estabelecido no Brasil o direito à participação na vida da comunidade e, nesse aspecto, a realização da Comigrar foi um marco ao conferir voz aos imigrantes residentes no Brasil. Como agente atuante na economia brasileira, como trabalhador que é, o imigrante contribui com o desenvolvimento do país e aqui se sujeita às leis e condutas administrativas, mais restritivas e em situação ainda mais desfavorável do que a de cidadãos brasileiros que também enfrentam problemas relativos às prestações de serviços públicos em todos os níveis.

Com fundamento nessas circunstâncias, o movimento internacional dos migrantes traz o lema "Aqui vivo, aqui voto", para lembrar aos poderes competentes sobre sua presença no país e a sua importância como força de trabalho e, quando regular, como contribuinte ativo e indispensável na sustentação do sistema previdenciário local.

O direito à participação política é, historicamente, negado aos estrangeiros e ainda constitui uma categoria que o define em relação ao nacional: o estrangeiro é aquele que não é cidadão, por isso estranho à ordem jurídica, estranho à organização do trabalho, estranho à comunidade, uma concepção, enfim, que não se adapta às condições reais, como as circunstâncias sociais efetivamente vividas em uma cidade ou em um bairro de uma grande cidade. Essa estraneidade não pode mais ser admitida, principalmente em razão de sua subjetividade, pois subjetivo é o conceito de estrangeiro, conforme bem ilustrado em emblemáticas obras literárias como $O$ Estrangeiro ou A Peste, ambas de Albert Camus. No mesmo sentido, a negação do direito de voto à população negra, na década de 1960, nos Estados Unidos, desencadeou o movimento pelas liberdades civis liderado por Martin Luther King. Na América do Sul, os povos originários também tiveram o seu direito de voto negado até meados da década de 1970, ou seja, sua participação política ativa e passiva é recente, posto que datada de menos de 50 anos. A vontade e disposição de ter uma participação ativa e cidadã, a contribuir para a solução dos problemas coletivos, não depende de sua condição de nacional ou estrangeiro, ou de sua etnia. Enfim, o fato de ser brasileiro ou não-brasileiro não é o que determina a disposição de colaborar com a vida em comunidade, pois em diversas situações da vida urbana os seus interesses convergem independentemente de seus caracteres genéticos ou do status jurídico em determinado território. Por isso, já são vários os Estados sul-americanos que admitem o voto do estrangeiro, ao menos nas eleições municipais. ${ }^{13}$

Embora o impacto da atuação dos governos locais seja mais evidente na vida cotidiana de todo cidadão, as políticas públicas no âmbito estadual também impactam no cotidiano do trabalhador imigrante, majoritariamente do microempreendedor ou do trabalhador contratado em razão de políticas de geração de emprego e desenvolvimento. Quanto à União, poder competente para a política migratória, ou seja, nos termos da Lei 6.815/80, pela determinação e controle sobre os critérios de entrada e permanência do imigrante, além de responsável pela fiscalização e pelos atos de conteúdo sancionatório, majoritariamente sujeitos ao exclusivo poder discricionário da administração pública.

Quando a matéria é relativa ao estrangeiro, o princípio do maior interesse do Estado e da segurança nacional é o princípio motivador para que as normas relativas aos imigrantes sejam, majoritariamente, de natureza administrativa e sujeitas a critérios de conveniência e oportunidade do governo em questão. É também o Poder Executivo federal o responsável pelos atos que estabelecem as práticas dos órgãos públicos com atribuições relativas aos imigrantes. Portanto, para uma democracia inclusiva, não apenas os

13 Constituição da Bolívia (art. 27); Constituição do Equador (art. 63); Constituição do Uruguai (art. 75); Constituição da Venezuela (art. 111); Constituição do Chile (art.14); Constituição do Paraguai (art. 120); Constituição da Colômbia (art.100). 
agentes políticos locais, mas também os estaduais e federais deveriam estar sob o crivo e controle externo de todos aqueles que se sujeitam às suas decisões legislativas e administrativas, incorporando os imigrantes nessa comunidade de pessoas diretamente interessadas no bem-estar público.

Por isso, em diversos países sul-americanos, em que pese serem países majoritariamente de emigração, reformas constitucionais foram feitas no sentido de conferir o voto ao estrangeiro, como é o caso do Uruguai, Paraguai, Bolívia, Equador, Chile, Colômbia e Venezuela. Na Colômbia, o direito de voto é uma possibilidade prevista na Constituição, que ainda depende de lei complementar para que se efetive. ${ }^{14} \mathrm{Na}$ Argentina, o direito à participação política e ao voto é concedido em algumas localidades e segundo a legislação local.

No Brasil, o atual governo municipal de São Paulo tem adotado uma política que admite ampla participação do imigrante nas consultas coordenadas pelas

14 Constituição da Bolívia. Artículo 27. I. (...). Il. Las extranjeras y los extranjeros residentes en Bolivia tienen derecho a sufragar en las elecciones municipales, conforme a la ley, aplicando principios de reciprocidad internacional. Constituição do Equador. Art. 63.- (...) Las personas extranjeras residentes en el Ecuador tienen derecho al voto siempre que hayan residido legalmente en el país al menos cinco años. Constituição da Venezuela. Artículo 111. (...) El voto para elecciones municipales podrá hacerse extensivo a los extranjeros, en las condiciones de residencia y otras que la ley establezca. Constituição do Uruguai. Artículo 73.- Los ciudadanos de la República Oriental del Uruguay son naturales o legales. Artículo 75.- Tienen derecho a la ciudadanía legal:A) Los hombres y las mujeres extranjeros de buena conducta, con familia constituida en la República, que poseyendo algún capital en giro o propiedad en el país, o profesando alguna ciencia, arte o industria, tengan tres años de residencia habitual en la República.B) Los hombres y las mujeres extranjeros de buena conducta, sin familia constituida en la República, que tengan alguna de las cualidades del inciso anterior y cinco años de residencia habitual en el país.C) Los hombres y las mujeres extranjeros que obtengan gracia especial de la Asamblea General por servicios notables o méritos relevantes. Constituição do Chile. ARTíCULO 14.- Los extranjeros avecindados en Chile por más de cinco años, y que cumplan con los requisitos señalados en el inciso primero del artículo 13, podrán ejercer el derecho de sufragio en los casos y formas que determine la ley.Constituição do Paraguai. ARTíCULO 120 - DE LOS ELECTORES Son electores los ciudadanos paraguayos radicados en el territorio nacional, sin distinción, que hayan cumplido diez y ocho años. Los ciudadanos son electores y elegibles, sin más restricciones que las establecidas en esta Constitución y en la ley. Los extranjeros con radicación definitiva tendrán los mismos derechos en las elecciones municipales. subprefeituras e criou, na Secretaria de Direitos Humanos e Cidadania, a Coordenadoria para Migrantes, que admite a presença de imigrantes em seus quadros e que desempenhou papel significativo no estímulo à conferência municipal realizada no âmbito da Comigrar e de conferências livres realizadas por imigrantes e associações civis.

Sobre esse aspecto, em relação à participação cidadã no território de destino, os imigrantes apresentaram proposta relativa ao seu direito à participação social e política, o que implica, no Brasil, em reforma constitucional, formulada nos seguintes termos: ${ }^{15}$

Promover o debate junto à sociedade brasileira e promover alterações constitucionais e legislativas necessárias a permitir o direito à elegibilidade, e ao voto, de modo a possibilitar o efetivo exercício da participação política, assim como também, permitir aos brasileiros residentes no exterior, o direito de elegerem seus representantes para cargos executivos e legislativos nacionais, estaduais e municipais.

Conscientes do significado histórico do direito de voto, da ruptura que isso representa com a tradição clássica, os participantes exortam, no início da proposta, à promoção de debate para conscientização da sociedade brasileira sobre a inadequação e inconveniência de se negar a participação política, o direito de eleger seus representantes e também de exercer mandatos populares, quando democraticamente esses mandatos the são legitimamente conferidos. Esse debate é imprescindível na sociedade e no Congresso Nacional, onde já se encontra em trâmite o PEC n²5/2012, de autoria do senador Aloísio Nunes, que garante aos imigrantes o direito de cidadania ativa e passiva nas eleições municipais. Aguarda-se, portanto, que se reconheça a importância e o significado da matéria para que se possa viabilizar a reforma constitucional necessária. ${ }^{16}$

15 Proposta 1.3. Formulada e/ou votada pelas CV Adus. SP,30.03.2014; CL Missão Paz.SP, 14.03.2014; CL Patrialnca.SP, 28.03.2014; Conferência Municipal (CM). SP.

16 CONSTITUIÇÃO DO BRASIL. Art. 14.A soberania popular será exercida pelo sufrágio universal e pelo voto direto e secreto, com valor igual para todos, e, nos termos da lei, mediante: [...] $§ 2^{\circ}$ Não podem alistar-se como eleitores os estrangeiros e, durante o período do serviço militar obrigatório, os conscritos. § $3^{\circ}$ São condições de elegibilidade, na forma da lei: I - a nacionalidade brasileira. 
Quando a proposta foi submetida à etapa final, os delegados nacionais destacaram a necessidade de ampliá-la e de tornar explícito que o direito político à participação deve incluir todas as esferas públicas, municipal, estadual e federal. Embora reivindiquem o direito do imigrante permanente de votar e ser votado, destacam também que outras formas de participação deverão ser admitidas por lei e estimuladas por meio de políticas administrativas.

Nesse sentido, foi também proposta a participação política do detentor de visto de estudante, o que pode ficar restrito ao âmbito de sua escola ou ampliado para abarcar a comunidade em que vive. Seria a exceção de uma situação já considerada especial, pois o estudante, embora migrante, possui criteriosamente um visto temporário, o que não admitiria o direito de voto nas eleições oficiais, presumindo-lhe a falta de interesse, já que sua permanência não se consolida em razão da natureza do seu visto. No entanto, como em outras situações, a restrição à participação nas eleições oficiais pode existir sem que isso represente a impossibilidade de exercer outras atividades de caráter político reguladas por outras esferas de poder e de instituições.

Interessante enfatizar que nas discussões acerca do acesso a direitos e igualdade de tratamento jurídico, quando destacado o direito dos presos, foi sugerido, principalmente por imigrantes de regiões de fora da América Latina, que além de cursos de português para estrangeiros fossem oferecidos cursos sobre a cultura brasileira. Quando o debate é relativo à participação política do estrangeiro, os imigrantes propõem a realização de cursos de formação política que lhes permitam identificar seus direitos, além de conhecer a organização dos poderes do Estado, a competência de cada um deles e como as desempenham. Essa formação, que é uma obrigação do Estado desde o ensino fundamental, exige tratamento e forma especial quando conferida ao imigrante.

Essa manifestação dos imigrantes é bastante significativa e evidencia a potencialidade que cada pessoa tem de exercer, no lugar onde vive, suas prerrogativas e deveres de cidadão, ou seja, prerrogativas e deveres decorrentes da vida em sociedade, onde escolheu trabalhar e estabelecer suas relações civis e, portan- to, também cívicas, isso é, relações que envolvem interesses e responsabilidades comuns, dirigidos à solução dos problemas da sociedade em questão.

A necessidade de conhecer seus direitos e as restrições que, no caso brasileiro, lhe são impostas aparece como apelo para a confecção de cartilhas em línguas diversas a serem disponibilizadas nos postos de chegada, pelos agentes de fronteira, ou seja, pela Polícia Federal. Trata-se de uma medida simples, que pode ser tomada de forma imediata pelos órgãos administrativos.

Conferir o direito político em sua amplitude ao imigrante, sem discriminações significativas em relação ao nacional, mas apenas coma exigência de tempo determinado de residência no Brasil, torna possível sua representação parlamentar, possibilita-lhe a propositura de ação popular, permite que seja ouvido em plebiscitos e referendos, o que não pode ser entendido como ameaça à soberania ou segurança, posto que esse exercício se dê nos estritos termos admitidos pela Constituição e normas infraconstitucionais que consagram seus valores e procedimentos democráticos.

\section{$7 \quad$ Acesso a cargos qualificados e carreira pública}

Entre as diferentes matizes de exploração e precarização do trabalho migrante, a impossibilidade ou, pelo menos, o enorme custo e a dificuldade impostos ao reconhecimento de suas qualificações profissionais são uns dos meios institucionais a sujeitar sua mão de obra a postos de pouca qualificação e com menores salários.

O reconhecimento de títulos, da forma como é estabelecido no Brasil, pela Lei de Diretrizes e Bases da Educação (Lei 9394/96), no seu art. 4817, delega às universidades públicas com curso equivalente o reconhecimento de diplomas estrangeiros. Estas, por sua vez, estabelecem a seu critério os requisitos que

17 BRASIL. Lei 9394/96. Art. 48. Os diplomas de cursos superiores reconhecidos, quando registrados, terão validade nacional como prova da formação recebida por seu titular. [...] § $2^{\circ}$ Os diplomas de graduação expedidos por universidades estrangeiras serão revalidados por universidades públicas que tenham curso do mesmo nível e área ou equivalente, respeitando-se os acordos internacionais de reciprocidade ou equiparação. 
serão exigidos para sua validação, exigindo prova do conteúdo das disciplinas e carga horária cursadas, realização de provas ou estágios suplementares, curso de disciplinas não cursadas, o que pode variar entre as diversas universidades públicas no Brasil, mesmo em cada uma delas, pode implicar regras diferentes para cada unidade ou departamento responsável pela avaliação da validação pretendida.

Em adição a esses embaraços, o imigrante necessita ainda do registro em entidades de representação profissional, que costumam opor óbices ao reconhecimento e validação de diplomas estrangeiros. Esses aspectos apareceram de forma recorrente em diversos grupos de trabalho na Comigrar. A identificação e o destaque conferidos ao problema permitem-nos inferir a presença significativa de migrantes com formação técnica e universitária subempregados, embora atendam, a princípio, os critérios de preferência estabelecidos pela Lei 6.815/80 e repetidos nos dois projetos em curso no Congresso Nacional, o PL 5655/2009 e o PL 2516/2015, que na concessão da permanência prioriza, expressamente, imigrantes qualificados, nos termos do parágrafo $2^{\circ}$ do seu art. 16.18

Esses casos estão, frequentemente, relacionados a pessoas que estariam habilitadas ao exercício de uma série de funções que poderiam ser estratégicas à sociedade e ao Estado, mas cujas habilidades e formação ficam, invariavelmente, perdidas. As consequências desse fenômeno são estudadas, porque são frequentes e são uma característica dos fluxos migratórios contemporâneos. Na maior parte dos deslocamentos transfronteiriços ocorre o chamado brainwaste (CAVALCANTI; OLIVEIRA; TONHATI, 2014:19-20). É comum que os imigrantes, no país de destino, desempenhem atividades aquém de suas habilidades e qualificações oficiais, havendo verdadeiro desperdício de talento, tanto para o país de origem quanto para o país de destino (ALONSO, 2011).

Além de mudanças no sistema de reconhecimento de

18 BRASIL. Lei 6.815/80. Art. 16. Parágrafo único. A imigração objetivará, primordialmente, propiciar mão de obra especializada aos vários setores da economia nacional, visando à Política Nacional de Desenvolvimento em todos os aspectos e, em especial, ao aumento da produtividade, à assimilação de tecnologia e à captação de recursos para setores específicos. diplomas estrangeiros, o acesso aos concursos públicos é outra forma de contornar barreiras ou, pelo menos, flexibilizar as normas relativas ao exercício, no Brasil, de trabalho especializado por imigrantes.

Não existe, na atualidade, justificativa razoável a impedir o acesso do imigrante a carreiras públicas, principalmente porque as regras de acesso são rigorosas para todos os participantes dos certames. Além disso, as demandas impostas pela nova ordem mundial exigem, em diversos órgãos públicos, especializações e habilidades nas quais a presença do imigrante seria altamente desejada, em face de seu conhecimento sobre costumes e línguas estrangeiras. 0 acesso a funções públicas traz, ainda, o benefício da efetiva inclusão social e política do imigrante, e atende a sua reivindicação por maior participação nos assuntos públicos, além de incorporar nas instâncias estatais, de forma pedagógica, o princípio da não discriminação.

Os participantes da Comigrar formularam, nesse sentido, a seguinte proposta19:

Assegurar o direito de migrantes e refugiados a inscrever-se e participar de concursos públicos, regulamentando critérios, para permitir o ingresso do migrante à função pública, até mesmo por contrato, revendo inclusive o quesito da naturalização e cidadania, ou estabelecendo tempo mínimo a partir do pedido de residência permanente no Brasil, para que o migrante possa concorrer à vaga pública, inclusive por meio de fórum específico para aprofundamento do debate junto ao Congresso Nacional.

$\mathrm{Na}$ etapa final, as contribuições complementares foram quase todas no sentido de se substituir o termo "segundo interesses nacionais", que veio grafado no texto original, pela permissão pura e simples, incondicionada, do acesso do imigrante aos concursos públicos. Essa mudança, de fato, é inócua, pois qualquer concurso estará vinculado aos temos do seu edital, que deverá necessariamente apresentar, caso a caso, a justificativa e critérios para sua realização.

19 Proposta 1.4. Cadernos Comigrar. Formulada/votada na $\mathrm{CL}$ MissãoPazPeru-SP, 14.03.2014. 
De resto, uma lei de migrações somente atenderá os interesses do imigrante conferindo-lhe status de igualdade, de fato e de direito, em relação aos nacionais, quando restringir ao máximo o recurso normativo da discricionariedade estatal, evitando termos como "conveniência nacional" ou "interesses nacionais". Em um Estado democrático de direito, a dignidade da pessoa deve ter primazia em relação à soberania do Estado.

\section{Conclusão}

As crescentes relações políticas e econômicas entre o Brasil e os demais Estados sul-americanos são indicadores do aprofundamento da integração entre eles, fator historicamente desestimulado entre estas nações, mas que tem quebrado tais barreiras desde a criação do Mercosul. Consequência dessa integração é o estímulo significativo aos fluxos migratórios inter-regionais, a evidenciar o impacto dos acordos mercossulinos e da recém-criada Unasul, na criação de novos parâmetros de relações internacionais entre os Estados da América do Sul, o que traduz o aumento do volume de negócios entre os Estados da região e das perspectivas socioeconômicas das populações envolvidas.

A pesquisa pôde constatar esse quadro e também o impacto da imigração internacional na demanda por políticas públicas nos locais de maior afluxo migratório, como é a cidade de São Paulo e seu entorno, mas também a demanda por políticas administrativas em nível federal, cujos órgãos têm a atribuição constitucional para os procedimentos de recepção e regularização da permanência do estrangeiro no Brasil, seja na condição de imigrante, propriamente dito, ou de refugiado.

Esta demanda resultou nos esforços empreendidos pelo governo federal, nos últimos dois anos, para a sistematização de dados oficiais acerca da imigração para o Brasil, que passaram a ser compilados a partir de 2014. Até então, não havia sequer a organização dos dados relativo aos pedidos regulares feitos ao CNIg, órgão do Ministério do Trabalho responsável pela edição da política migratória brasileira e autorização para a concessão de visto de permanência, associado ao exercício de trabalho, no Brasil. Os dados arquivados junto ao Departamento da Polícia Federal, vinculado ao Ministério da Justiça, ainda permane- cem sem sistematização, o que inviabiliza sua análise.

Em novembro de 2014, foi criado o Observatório das Migrações, órgão de pesquisa da UnB, que, mediante convênio com o MTE, organizou os dados disponíveis na Relação Anual de Informações Sociais (RAIS), declarada pelas empresas, e nos requerimentos de trabalho processados junto ao CNIg (OLIVEIRA, TONHATI; 2015,1-8).De qualquer forma, por meio dessas bases, são identificados somente os imigrantes regularizados ou em processo de regularização, permanecendo na invisibilidade todo o universo de imigrantes indocumentados, número que continua sendo fixado por estimativas, que geralmente indicam um acréscimo de cerca de $30 \%$ em relação à população migrante em situação regular (ALONSO, 2011).

Com os dados obtidos, evidenciou-se que o Brasil está muito distante de ser comparado com os países que atraem imigrantes, ao contrário do que parece indicar a mídia brasileira, que costuma reportar uma “invasão de estrangeiros" nos últimos anos. Ao contrário, em 2010, a presença de imigrantes no Brasil era de 592.591 pessoas. Na realidade, esses números demonstram que houve um decréscimo em relação ao ano de 2000, quando se registrava a presença de 683.836 estrangeiros no país (OLIVEIRA; 2015,53).

No entanto, as denúncias sobre a exploração de trabalho de sul-americanos e sobre a chegada de haitianos, largamente divulgadas pela imprensa, sugerem, erroneamente, esta "invasão" a ameaçar a segurança e estabilidade nacional. Os índices demonstram que o número de imigrantes no Brasil, mesmo considerando o acréscimo dos indocumentados, constitui apenas $0,3 \%$ da população total brasileira, que é de 193.946.886, segundo o censo de 2012. Essa proporção, que não chega a 1\%, é, portanto, muito inferior à de qualquer país da OCDE, composta por países europeus, Estados Unidos e países asiáticos desenvolvidos (IBGE, 2012).

Apesar da insignificante proporção de imigrantes no Brasil, algumas cidades brasileiras viram-se na contingência de responder a uma nova realidade migratória, atendendo a demandas por políticas públicas voltadas a essa população, principalmente em relação àqueles que se encontram em situação de alta 
vulnerabilidade, e, apesar dos acordos de residência firmados no âmbito do Mercosul, vigentes desde 2009, considerável número de sul-americanos entre esses (OLIVEIRA, 2015, 61).

Com a realização da Comigrar, organizada com o objetivo de descortinar essa realidade, os imigrantes puderam se manifestar sobre os gargalos legais e procedimentais que dificultam ou impedem o acesso de trabalhadores imigrantes a direitos, e tal desafio foi cumprido em parte.

Para uma solução satisfatória das questões colocadas pelos participantes da Comigrar, e também para atender às necessidades impostas ao Estado diante da nova conjuntura global de migrações internacionais, faz-se ainda necessária a criação de novos indicadores nos censos demográficos e a abertura dos arquivos da Polícia Federal, de forma a subsidiar a administração pública, em todas assuas esferas, acerca do número e localização precisa da população de imigrantes. Igualmente, impõe-se a necessidade de uma profunda reforma legislativa, acompanhada de emendas constitucionais, hábeis a alterar os paradigmas jurídicos relativos aos estrangeiros no Brasil, incorporando-os, finalmente, ao sistema de direitos civis e sociais em condição de efetiva igualdade jurídica com os nacionais.

Apesar dos dois projetos de lei em trâmite no Congresso Nacional, o PL 5655/2009 e o PL 2516/2015, e também de um projeto de emenda constitucional, o PEC 25/2012, sobre direitos políticos, as mudanças vêm em ritmo lento e pontual, feitas mediante resoluções normativas ministeriais; medidas, portanto, insuscetíveis de alterar o sistema legal de exceção representado pelo atual Estatuto de Estrangeiros vigente no Brasil.

1111111111111111111111111111111111

\section{Referências}

CALAVITA, Kitty.Inside the State: the Bracero Program and Immigration. New Orleans: Quid pro Books, 2010.

CAVALCANTI, Leonardo; TONHATI, Tania. As migrações internacionais no Brasil: construindo ferramentas para a análise-Observatório das $\mathrm{Mi}$ grações Internacionais no Brasil. In: Cadernos ObMigra. V. 1, n. 1, 2015, p. 1-8.

BAUMAN, Zygmund. Comunidad: en busca de seguridaden um mundo hostil. Madrid: SigloVeinteuno, 2003.

BRASIL. Lei $6.815 / 80$, que define o Estatuto do Estrangeiro. Disponível em: <http://www.planalto.gov.br/ccivil_03/leis/l6815.htm>. Acesso em: 17.mar.2015.

BRASIL. LEI 9474/97, que define o Estatuto do Refugiado. Disponível em: <http://www.acnur.org/ t3/fileadmin/Documentos/portugues/Publicacoes/2010/Lei_947497_e_Coletanea_de_Instrumentos_de_Protecao_Internacional_dos_Refugiados.pdf?view=1>. Acesso em: 14 jan. 2015

BRASIL. Acordo Bilateral sobre Regularização Migratória. Disponível em: <http://portal.mte.gov.br/data/files/FF8080812D0A02C0012D0DF379886073/acordo.pdf>. Acessoem: 14mar.2015.

Business for Social Responsibility. (2008) Business International Labor Migration: a Responsible Role for Business.Disponível em: <http://www.bsr.org/reports/BSR_LaborMigrationRoleforBusiness.pdf>. Acesso em: 20 out. 2014.

HIRATA, Helena (2009). A precarização e a divisão internacional e sexual do trabalho. Sociologias. n²1. Porto Alegre jan./june 2009. Disponível em: <http://www.scielo.br/scielo.php?pid=S1517$-45222009000100003 \&$ script=sci_arttext $>$. Acesso em: 15 mar.2015.

INSTITUTO BRASILEIRO DE GEOGRAFIA ESTATISTICA. Estimativas de população. Tabela de estimativas Brasil e Unidades da Federação, 2012. Disponível em: <http://www.ibge.gov.br/home/estatistica/ populacao/estimativa2012/estimativa_tcu.shtm> Acesso em 08.dez.2016.

MINISTÉRIO DA JUSTIÇA (2014). I Conferência Nacional sobre Imigração e Refúgio. Caderno de Propostas. Disponível em: <http://pt.slideshare.net/justicagovbr/comigrarpropostas>. Acesso em: 17 mar. 2015. 
MERCOSUR. Acuerdo sobre Residencia para Nacionales de los Estados Partes del Mersosur. Disponível em: <http://www.mercosur.int/t_generic.jsp?con tentid $=526 \&$ site $=1 \&$ channel=secretaria $>$. Acesso em: 18 mar. 2015.

MERCOSUR. Acuerdo Multilateral de Seguridad Social del Mercado Común del Sur y suReglamento Administrativo para la Aplicación del Acuerdo. Disponível em: <http://www.mercosur.int/t_generic. jsp? contentid=526\&site $=1 \&$ channel=secretaria $>$. Acesso em: 18 mar. 2015.

MERCOSUR. Acuerdo contra el Trafico Ilicito de Migrantes entre los Estados Partes del Mersosur. Disponível em: <http://www.mercosur.int/t_generic. jsp? contentid=526\&site=1\&channel=secretaria $>$. Acesso em: 18 mar. 2015.

MERCOSUR. Protocolo de Asunción sobre Compromiso com laPromocion y Protección de los Derechos Humanos del Mercosur. Disponível em: <http:// www.mercosur.int/t_generic.jsp?contentid=526\& site $=1 \&$ channel=secretaria $>$. Acesso em: 18 mar. 2015.

MERCOSUR. Acuerdo sobre Regularización Migratoria Interna de Ciudadanos del Mercosur, Bolivia y Chile. Disponível em: <http://www.mercosur. int/t_generic.jsp?contentid=526\&site $=1 \&$ channel =secretaria>. Acesso em: 18 mar. 2015.

MERCOSUR. DECLARACÃO SOCIOLABORAL DO MERCOSUL. Disponível em:

<http://www.mercosur.int/innovaportal/file/2485/1/ cmc_1998_ata02_declaracion_es_sociolaboral. pdf>. Acesso em: 23 set. 2014.

OLIVEIRA, Antonio Tadeu. O perfil geral dos imigrantes no Brasil a partir dos censos decmográficos de 2000 e 2010. In: Cadernos ObMigra, v.1, n. 2, 2015. Disponível em: <http://periodicos.unb.br/index. php/obmigra/article/view/14895>. Acesso em 08. Dez. 2016

PAULON, Simone Maineri (2003) A análise de implicação como ferramenta na pesquisa-intervenção. Disponível em: <http://www.scielo.br/pdf/psoc/ v17n3/a03v17n3>. Acesso em: 20 mar. 2015.

RODRIGUEZ, José Alonso (2010).International migration and development: a review in light of crisis. Disponívelem: <http://www.un.org/en/development/desa/policy/cdp/cdp_background_papers/ bp2011_11e.pdf>. Acesso em: 24 mar. 2015.
THIOLLENT, Michel. (2002) Construção do conhecimento e metodologia da extensão. Disponível em: <http://www.prac.ufpb.br/anais/Icbeu_anais/ anais/conferencias/construcao.pdf>. Acesso em: 20 mar. 2015.

Data de submissão/Submission date: 14.09.2015.

Data de aceitação para publicação/Acceptance date: 04.05.2017. 